\title{
TIME COURSE OF CHANGES IN PROTEIN SYNTHESIS IN MARCAINE-INDUCED SKELETAL MUSCLE REGENERATION
}

\section{GEORGE H. JONES}

Department of Cellular and Molecular Biology, Division of Biological Sciences, The University of Michigan, Ann Arbor, MI 48109 (U.S.A.)

(Received April 2nd, 1984)

\section{SUMMARY}

The time course of the regeneration of rat skeletal muscle has been examined after injection of the myotoxic drug, Marcaine, to induce regeneration. Muscle wet weight decreases during the initial phase of the regeneration process while the ability of the regenerating muscle to incorporate $\left[{ }^{35} \mathrm{~S}\right]$ methionine into protein, the yield and activity of muscle polysomes and the yield of total and poly(A) + RNA all increase initially. Following the initial changes, these parameters return to near control values by 30 days after Marcaine injection. Theoretical calculations suggest that the changes in polysome yield and activity are sufficient to account for the changes in the ability of muscle fragments to synthesize protein during the regeneration process. The specific activity of total muscle RNA in the wheat germ cell-free system decreases initially during the early stages of the regeneration process. This decrease may reflect the fact that while the yields of both total and poly $(\mathrm{A})+$ RNA increase during the early stages of regeneration, the percentage of the total RNA which is poly $(A)+$ decreases initially.

Key words: Marcaine; Muscle regeneration; Protein synthesis

\section{INTRODUCTION}

It has been known for some years that damaged skeletal muscle has the capacity to regenerate itself [1]. A particularly useful model for the study of the regeneration process involves the induction of regeneration by the use of a myotoxic drug known as Marcaine (bupivacaine). It has been shown by Hall-Craggs [2], by Carlson and Gutmann [3] and by others [4,5] that the injection of Marcaine into an appropriate muscle leads to a rapid and striking degeneration of that muscle which is followed by an equally dramatic regeneration phenomenon.

Previous studies from this laboratory have shown that Marcaine is a translational 
inhibitor which acts at the level of the aminoacylation of RNA [6,7]. The inhibitory effect is specific for eukaryotic cells and involves the competitive inhibition of the acylation of tRNA with certain amino acids [7]. This effect on protein synthesis may explain, in part, the efficacy of Marcaine in the induction of muscle degeneration. More recent studies have been concerned with the changes in protein synthesis whici, occur during regeneration of rat skeletal muscle. It has been shown that Marcaine injections of $0.5-1.5 \%(\mathrm{w} / \mathrm{v})$ in saline are efficient in inducing breakdown and regeneration of rat tibialis anterior, and that dose-dependent changes in protein synthesis accompany the regeneration process. This increase in protein synthesis seems to reflect an increase in the yield and activity of polyribosomes isolated from regenerating as compared with control muscle [8].

In view of the results summarized above which indicate that changes in the translational apparatus do occur during skeletal muscle regeneration, it is of interest to determine what molecular effects are responsible for the observed increases in protein synthesis. To this end, the time course of the regeneration process has been examined. Polyribosomes, total and poly(A) + RNA have been isolated at various times during regeneration and translated in cell-free protein-synthesizing systems. The results of these experiments are discussed in terms of the regulation of protein synthesis during muscle regeneration.

\section{EXPERIMENTAL METHODS}

\section{Marcaine injection procedure}

Skeletal muscle regeneration was induced by the direct injection of $0.75 \%(\mathrm{w} / \mathrm{v})$ solutions of Marcaine in $0.9 \% \mathrm{NaCl}$ into the tibialis anterior of male rats as described previously [8]. This Marcaine dose induces extensive muscle regeneration with little or no ischemia. Contralateral control muscles were injected with saline only. Muscles were excised for examination $5,8,15$ and 30 days following injection.

\section{Measurement of muscle protein synthesis}

The procedure for incorporation of $\left[{ }^{35} \mathrm{~S}\right]$ methionine by muscle fragments was as described previously [8]. Procedures for isolation of muscle polyribosomes and for cell-free protein synthesis have been described, and calculation of relative levels of protein synthesis were made exactly as was described in a previous publication [8] .

\section{Protein synthesis in the wheat germ system}

Total and poly(A) + muscle RNAs were isolated by Method 3 of Rogers and Jones [9]. The RNAs were translated in the micrococcal nuclease treated wheat germ cell-free system [10]. In most incubations, reaction mixtures contained the following components: Tris $-\mathrm{HCl}$, pH 7.6, $20 \mathrm{mM}$; potassium acetate, $56 \mathrm{mM}$; nineteen non radioactive amino acids minus methionine, $0.04 \mathrm{mM}$ each; creatine phosphokinase, $0.2 \mathrm{mg} / \mathrm{ml}$; magnesium acetate, $2.5 \mathrm{mM}$; ATP, $1 \mathrm{mM}$; GTP, $0.1 \mathrm{mM}$; phosphocreatine, $5 \mathrm{mM}$; dithio- 
threitol, $2 \mathrm{mM}$; spermidine, $0.2 \mathrm{mM}$; human placental ribonuclease inhibitor, 200 units/ $\mathrm{ml} ;\left[{ }^{35} \mathrm{~S}\right]$ methionine $200 \mu \mathrm{Ci} / \mathrm{ml}$. Reaction mixtures were incubated for $60 \mathrm{~min}$ at $25^{\circ} \mathrm{C}$ and trichloroacetic acid precipitates were collected on glass fiber filters to quantitate methionine incorporation.

\section{RESULTS}

\section{Time course of changes in muscle mass and capacity for protein synthesis}

When regenerating rat tibialis anterior was subjected to histological analysis by hematoxylin and eosin staining, the time course of regeneration in morphological terms was shown to be identical to that observed by other workers $[2,11]$. By 5 days post injection, myoblast fusion had occurred and late regenerating myotubes could be observed [2,11]. By 8 days, the transformation from myotubes to early cross-striated muscle fibers could be observed. Fifteen-day regenerates looked much like mature muscle and by 30 days the regenerates were indistinguishable from normal muscle or saline-injected controls $[2,11]$. It was of interest, therefore, to determine how the regeneration process affected the ability of the regenerating muscle to synthesize protein. Figure $1 \mathrm{~A}$ shows the change in the muscle wet weight to animal body weight ratio over the course of the regeneration process. Regeneration occasions an initial decrease in the muscle weight which is followed by a gradual increase. By 30 days post injection the muscle weight has returned to near control values.

Figure $1 \mathrm{~B}$ shows the change in ability of muscle fragments to incorporate $\left[{ }^{35} \mathrm{~S}\right]$ methionine into protein over the course of regeneration. In these experiments, minced muscle was incubated with the radioactive precursor as previously described [8]. It can

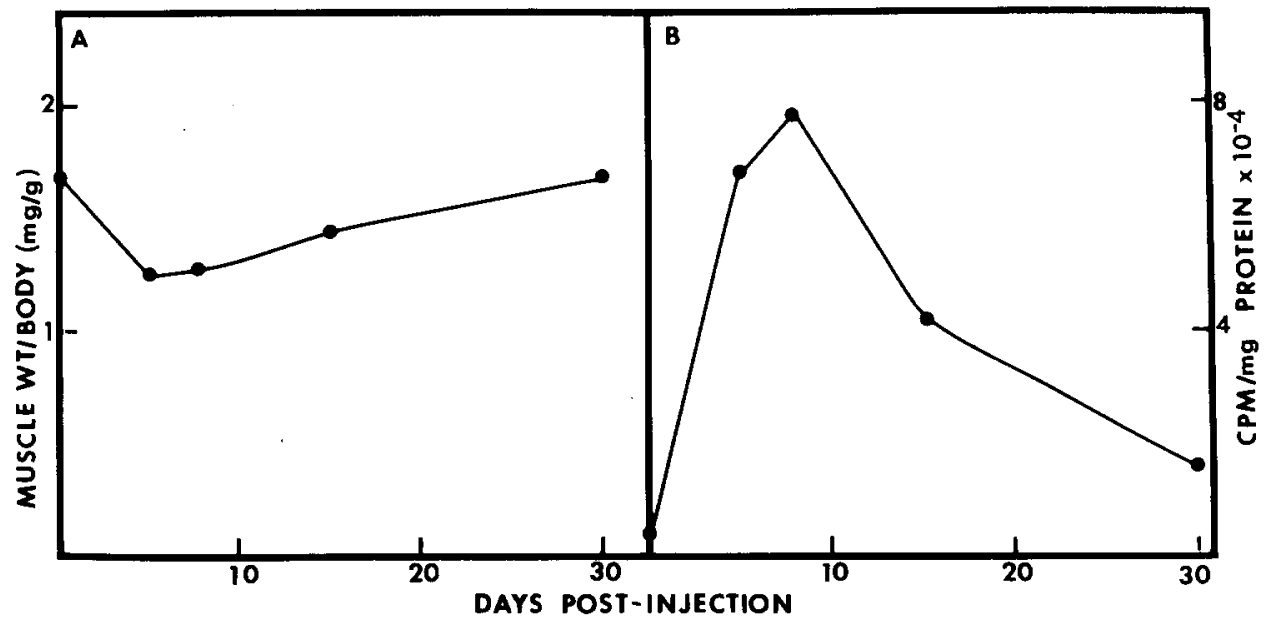

Fig. 1. (A) Changes in muscle wet weight to animal body weight ratio over the course of the regeneration process. (B) $\left[{ }^{35} \mathrm{~S}\right]$ Methionine incorporation by fragments of control and Marcaine-treated muscle. The control values are shown at zero time on the vertical axis. 
be seen that there is a dramatic increase in the ability of the regenerating muscle to incorporate $\left[{ }^{35} \mathrm{~S}\right]$ methionine into an acid-insoluble form during the early stages of regeneration. The maximum incorporation increase (about 20 -fold as compared with controls) was achieved 8 days following Marcaine injection. The capacity for protein synthesis declined after that point and by 30 days post injection, the level of $\left[{ }^{35} \mathrm{~S}\right\}$ methionine incorporation was essentially identical to that of control muscle.

\section{Protein synthesis by polyribosomes from regenerating tibialis anterior}

In an earlier report from this laboratory, it was argued that the dose-dependent increase in protein synthesis observed 5 days following Marcaine injection was due, at least in part, to an effect at the level of the muscle polyribosomes [8]. To test this hypothesis further, polysomes have been isolated from regenerating muscle at various times following Marcaine injection. The time course of the regeneration effect on the yield of polyribosomes is shown in Fig. 2A. There is a dramatic increase in the polysome content of regenerating muscle at the early time points ( 5 and 8 days) following Marcaine injection with a gradual decrease to near control levels by 30 days.

The protein synthetic activity of the isolated polysomes was tested in the polysomal cell-free protein synthesizing system described previously [8]. Results of a typical analysis are shown in Fig. 2B. In this experiment, the ability of the polysomes to direct the incorporation of $\left[{ }^{35} \mathrm{~S}\right]$ methionine into protein was determined, and the specific activity (cpm incorporated per $\mathrm{A}_{260}$ unit polysomes) was calculated from the linear portion of polysome versus incorporation curves (see ref. 8 for typical curves). Again,

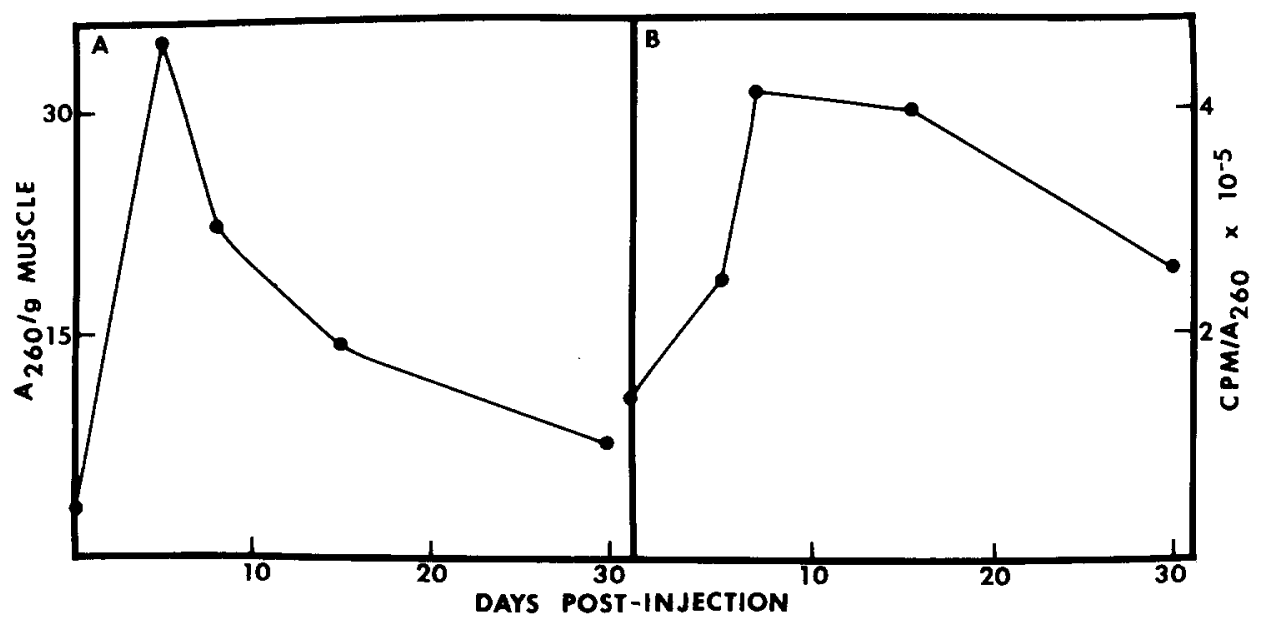

Fig. 2. (A) Changes in the yield of polyribosomes over the course of the regeneration process. Polysomes yields are expressed as $A_{260}$ units recovered per $\mathrm{g}$ of starting muscle tissue. (B) Specific activity of muscle polysomes. Polysomes were translated in a cell-free system and specific activities were determined from the linear portion of curves depicting the dependence of incorporation levels on polysome concentration. Control values are shown at zero time on the vertical axis. 
significant increases in the cell-free synthetic activity of the polysomes are observed at the early time points after Marcaine injection and the activity decreases gradually, approaching control levels by 30 days following the induction of regeneration. It is important to note here that polysomal cell-free systems contained a soluble enzyme fraction from rat liver so that the increases depicted in Fig. 2 cannot be due to changes at the level of the soluble enzymes.

It was suggested in the previous report that the increase in protein synthesis observed with regenerating muscle fragments was explainable in terms of the increase in yield and activity of the muscle polysomes [8]. Table I shows the relative levels of $\left[{ }^{35} \mathrm{~S}\right]$ methionine incorporation by muscle fragments over the 30-day course of the regeneration process studied here (column 2). The third column in the table reflects the results of theoretical calculations in which the effects of polysome yield and activity on overall protein synthesis levels have been estimated. At each time point, the relative increase in polysome yield compared to controls was multiplied by the relative increase in activity. For example, at the 5-day-point, the relative increase in yield was 10.6 -fold compared to control muscle, and the increase in activity was 1.7 -fold. Thus, the expected increase in the level of protein synthesis is $1.7 \times 10.6$ or 18 -fold. This figure is in excellent agreement with the observed level of protein synthesis (18.7 times control) by fragments 5 days following the induction of regeneration. Indeed, the correlation between the calculated and observed protein synthesis levels was excellent at all time points examined (Table I). Experiments are in progress to determine the molecular alterations responsible for the increased activity of polysomes isolated from regenerating muscle, and to examine other components of the translational apparatus (e.g. tRNA) in regenerates.

Isolation of total and poly $(A)+R N A$ from control and regenerating muscle

To examine further the effects of the regeneration process on the synthesis of muscle

\section{TABLE I}

CALCULATED AND EXPERIMENTAL PROTEIN SYNTHESIS LEVELS IN CONTROL AND REGENERATING SKELETAL MUSCLE

\begin{tabular}{lcc}
\hline $\begin{array}{l}\text { Days post } \\
\text { injection }\end{array}$ & $\begin{array}{l}\text { Measured protein } \\
\text { synthesis level }\end{array}$ & $\begin{array}{l}\text { Calculated protein }^{\mathbf{a}} \\
\text { synthesis level }^{\mathbf{b}}\end{array}$ \\
\hline Control & 1.0 & 1.0 \\
5 & 18.7 & 18.0 \\
8 & 21.6 & 19.3 \\
15 & 11.4 & 11.8 \\
30 & 4.4 & 4.1 \\
\hline
\end{tabular}

${ }^{a}$ Determined from the results of Fig. $1 \mathrm{~B}$ and expressed relative to the control value set arbitrarily at 1.0 .

${ }^{\mathrm{b}}$ Calculated from the data of Fig. 2A and B. The yields and activities of the muscle polysomes at each time point were expressed relative to control values set arbitrarily at 1.0. The relative yield was then multiplied by the relative activity at each time point to obtain the data in column three. 
proteins, total and poly $(\mathrm{A})+\mathrm{RNA}$ were isolated from the muscle tissue. The isolation procedure (Method 3) of Rogers and Jones [9], which mimics that of Glisin et al. [12], was used for the isolation of total RNA, and poly(A) + RNA was isolated by oligo(dT). cellulose chromatography. The yields of total and poly $(A)+$ RNA over the course of the regeneration process are shown in Table II. It can be seen that there is a dramatic increase in the yield of total RNA from the regenerating muscle as compared with controls. By 8 days post injection, there is five times as much RNA isolatable from regenerates as from controls. A similar increase in the yields of poly(A) + RNA is also observed. The amounts of RNA decrease after the 8-day maximum and approach control levels by 30 days following Marcaine injection. It is of interest to note that while there is an increase in the absolute amount of poly(A) + RNA in regenerating muscle, there is a decrease in the relative amount of this RNA fraction as compared to controls. Thus, poly (A) + RNA is only $1.1 \%$ of the total in 5-day regenerates while it represents $1.7 \%$ of the total in control muscle. The percentage of poly $(A)+$ RNA gradually increases over the course of the regeneration process, approaching control levels by 30 days.

\section{Protein synthesis using total and poly $(A)+R N A$}

The coding capacity of total and poly $(\mathrm{A})+$ RNA has been examined by cell-free protein synthesis in the wheat germ in vitro system. This system has been shown previously to translate mRNAs from muscle tissue with efficiency and fidelity $[13,14]$. The responses of the wheat germ system to total and poly(A) + RNAs are shown in Fig. $3 \mathrm{~A}$ and $B$. Both RNA preparations stimulated $\left[{ }^{35} \mathrm{~S}\right]$ methionine incorporation significantly and, as expected, poly(A) + RNA was a more effective template, per $\mu \mathrm{g}$ of RNA added, than was total muscle RNA (note the differences in scale in Fig. $3 \mathrm{~A}$ and $\mathrm{B}$ ). The results shown in Fig. 3 were obtained with RNAs isolated from control muscle but similar data were obtained when RNAs from regenerating muscle were tested. Total RNA routinely stimulated amino acid incorporation in the wheat germ system from 12- to 20 -fold while poly (A) + RNA stimulated from 40- to 90 -fold.

\section{TABLE II}

YIELDS OF TOTAL AND POLY(A)+ RNA AT VARIOUS TIMES DURING SKELETAL MUSCLE REGENERATION

\begin{tabular}{lcc}
\hline $\begin{array}{l}\text { Days post } \\
\text { injection }\end{array}$ & $\begin{array}{l}\text { Total RNA } \\
(\mu g / g \text { muscle) }\end{array}$ & $\begin{array}{l}\text { Poly } A(+) R N A \\
(\mu g / g \text { muscle })\end{array}$ \\
\hline Control & 284 & $4.3(1.7)$ \\
5 & 1375 & $13.8(1.1)$ \\
8 & 1450 & $18.7(1.4)$ \\
15 & 895 & $13.0(1.6)$ \\
30 & 365 & $5.9(1.6)$ \\
\hline
\end{tabular}

\footnotetext{
${ }^{a}$ Calculated by assuming that $50 \mu \mathrm{g}=1 \mathrm{~A}_{260}$ unit of RNA. Yields are expressed relative to muscle wet weight.

${ }^{b}$ Numbers in parentheses represent the percentage of total RNA which was recovered as poly $(A)+$ RNA.
} 


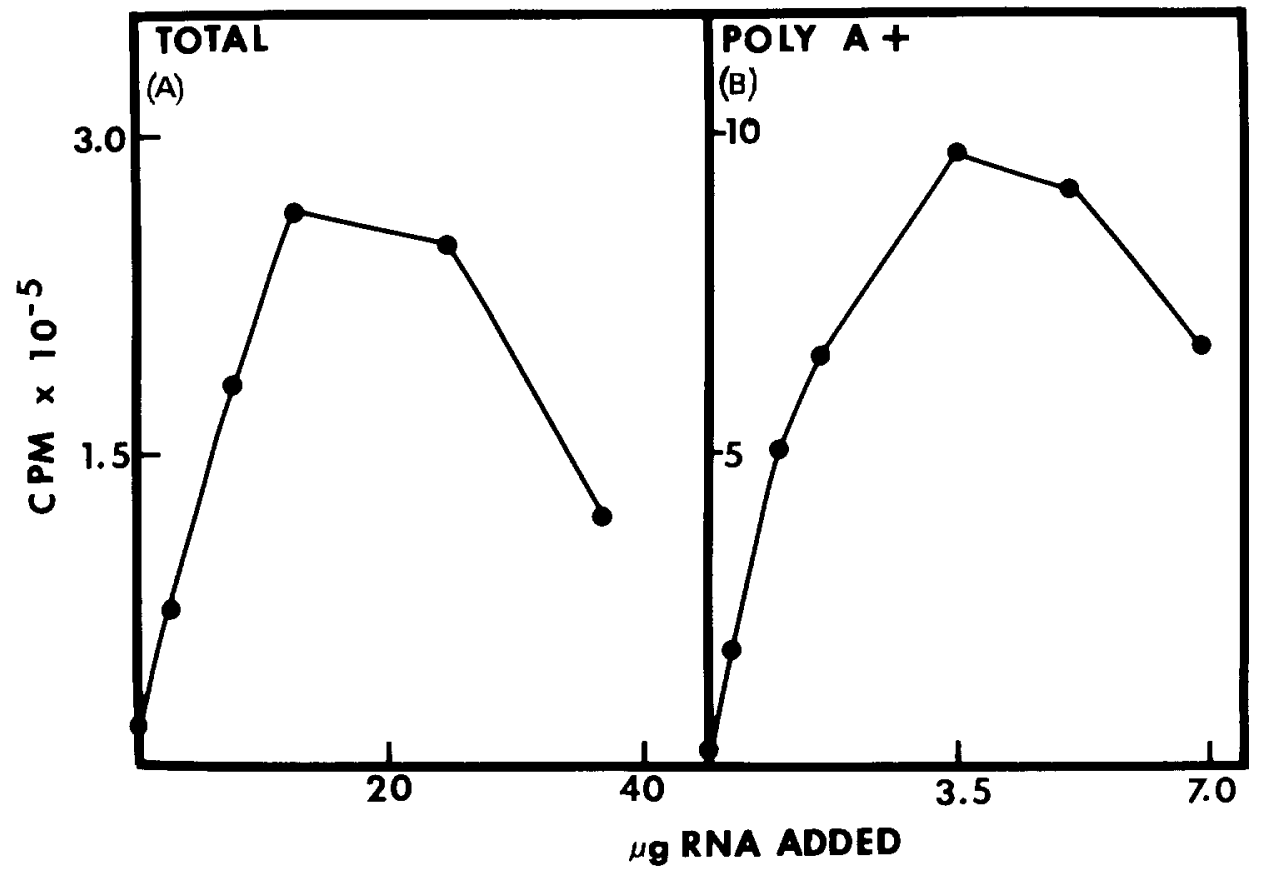

Fig. 3. Stimulation of cell-free protein synthesis in the wheat germ system by total (A) and poly (A)+ (B) muscle RNA. Data in the figure represent incorporation levels in a 50- $\mu$ leaction mixture in response to the indicated levels of added RNA. Note the difference in scale in the two parts of the figure.

Figure 4 depicts the specific activity of total RNA isolated at various times during the regeneration process. $\mathrm{cpm} / \mu \mathrm{g}$ RNA were determined for each RNA preparation from curves similar to those presented in Fig. 3A. Figure 4 shows that the specific activity of the RNA decreases 5 days following Marcaine injection and gradually returns to control levels over the next 25 days. This result may reflect the decrease in relative poly $(A)+$ RNA content in the total RNA population isolatable from regenerating muscle (Table II).

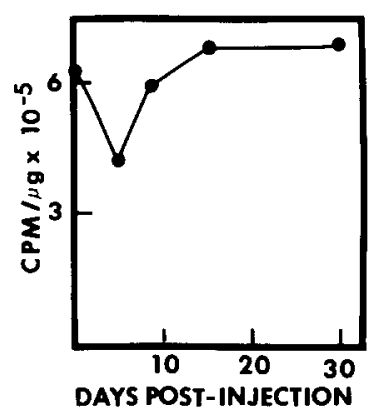

Fig. 4. Specific activity of total RNA preparations in stimulating $\left[{ }^{35} \mathrm{~S}\right]$ methionine incorporation in the wheat germ system. Specific activities were determined from the linear portion of curves depicting the dependence of $\left[{ }^{35} \mathrm{~S}\right]$ methionine incorporation on the concentration of RNA in the reaction mixtures. The control value is shown at zero time on the vertical axis. 


\section{DISCUSSION}

The results presented confirm that skeletal muscle regeneration in rats is accompanied by dramatic changes in the activity of the translational apparatus. There are increases in the yields and activities of polysomes isolated from regenerates early in the regeneration process, and these increases can be used to explain the observed increase in the ability of muscle fragments to incorporate radioactive precursors into protein. The increased protein synthetic activity also seems to reflect an increase in the amount of messenger RNA present in the regenerating muscles. Such an increase is not surprising since considerable synthesis of new protein must be required to rebuild the damaged muscle. Following the initial increase in yield and activity of polysomes and RNA, there is a gradual decrease so that by 30 days following the induction of regeneration, yield and activity values have returned to near control levels.

As mentioned previously, the morphological time course of the regeneration process observed in the experiments reported above was identical to that found by other researchers $[2,11]$. It is of interest to attempt to correlate the changes in protein synthesis with the morphological stages of the regeneration process which have been characterized in previous publications. By 5 days after Marcaine injection, regenerating myotubes can be observed morphologically [2,11] and the muscle shows an increased capacity for protein synthesis and an increased yield of polyribosomes and of total and poly $(\mathrm{A})+$ RNA (Figs. 1-3). These increases are likely to reflect the synthesis of contractile proteins for the construction of new myofibrils and are even more dramatic when 8-day regenerating muscle is examined. By this time, early cross-striated muscle fibers can be seen histologically $[2,11]$, and the need for newly synthesized contractile proteins is presumably high. The decline in the protein synthetic parameters examined in this study after the 8-day time point is probably indicative of a decreased requirement for new proteins once mature muscle fibers have been formed. It is noteworthy that the activity of total muscle RNA in the wheat germ cell free system actually decreases during the early stages of the regeneration process (Fig. 4). This observation may simply reflect the decrease in percentage of poly $(\mathrm{A})+\mathrm{RNA}$ in the total population at the earliest time points following Marcaine injection (Table II). The reason for these decreases has not yet been determined.

A previous report from this laboratory showed that myofibrillar proteins corresponding to myosin heavy chain and actin could be detected on one-dimensional polyacrylamide gel electrophoresis of the products of polysomal protein synthesis [8]. In the present study, it was observed that one-dimensional gel profiles of the products of polysomal and RNA primed wheat germ protein synthesis were indistinguishable from those previously published $[8,9]$. Experiments are in progress to quantitate the levels of myosin heavy chain and actin synthesis during regeneration using immunological techniques and two-dimensional gel electrophoresis. 


\section{ACKNOWLEDGEMENTS}

This research was supported by Grant No. PCM-7904260 from the National Science Foundation and Grant NS-17017 from the USPHS, National Institute of Neurology and Communicative Disorders and Stroke.

\section{REFERENCES}

1 B.M. Carlson, Am. J. Anat., 137 (1973) 119-149.

2 E.C.B. Hall-Craggs, Exp. Neurol., 43 (1974) 349-358.

3 B.M. Carlson and E. Gutmann, Pflugers Arch., 353 (1975) 227-239.

4 P.W. Benoit and W.D. Belt, J. Anat., 107 (1970) 547-556.

5 I. Jirmanova and S. Thesleff, Z. Zellforsch., 131 (1972) 77-97.

6 M.E. Johnson and G.H. Jones, Biochem. Pharmacol., 27 (1978) 1753-1757.

7 G.H. Jones, Biochemistry, 18 (1979) 4452-4457.

8 G.H. Jones Muscle Nerve, 5 (1982) 281-290.

9 P.A. Rogers and G.H. Jones, Can. J. Biochem., 60 (1982) 587-592.

10 R.B. Devlin and C.P. Emerson, Jr., Cell, 13 (1978) 599-611.

11 K.R. Wagner, B.M. Carlson and S.R. Max, J. Neurol. Sci., 34 (1977) 373-390.

12 V. Gilsin, R. Crkvenjakov and C. Byus, Biochemistry, 13 (1974) $2633-2637$.

13 S. Benoff and B. Nadal-Girard, Biochemistry, 18 (1979) 494-500.

14 R.B. Devlin and C.P. Emerson, Jr., Dev. Biol., 69 (1979) 202-216. 